\title{
COMPARISON BETWEEN DEXMEDETOMIDINE AND A COMBINATION OF MIDAZOLAM AND FENTANYL FOR SEDATION DURING AWAKE FIBEROPTIC INTUBATION - A PROSPECTIVE RANDOMIZED PARALLEL GROUP DOUBLE-BLINDED STUDY
}

\author{
K. Murugesan', P. Rajkumar²
}

${ }_{1}^{1}$ Associate Professor, Department of Anaesthesiology, Government Mohan Kumaramangalam Medical College, Salem, Tamilnadu, India.

${ }^{2}$ Assistant Professor, Department of Anaesthesiology, Government Mohan Kumaramangalam Medical College, Salem, Tamilnadu, India. ABSTRACT

\section{BACKGROUND}

Peter Murphy, in England, in 1965 used a fiberoptic choledocosope to intubate nasally a patient with Still's disease. Fiberoptic nasotracheal intubation is one of the techniques available for the management of patients with difficult airways.

This study compares the effectiveness and safety of dexmedetomidine with a combination of fentanyl and midazolam for procedural sedation during awake fiberoptic intubation.

\section{MATERIALS AND METHODS}

This was a single centre, prospective, randomised, parallel group, double-blinded study. To compare the effectiveness and safety of dexmedetomidine with a combination of fentanyl and midazolam for procedural sedation during awake fiberoptic intubation. Data was analysed using Sigma Stat 3.5 version.

\section{RESULTS}

This study shows that dexmedetomidine is a safe and highly efficacious drug in providing sedation, amnesia, anxiolysis, analgesia, better haemodynamics without producing respiratory depression for awake fiberoptic intubation.

\section{CONCLUSION}

We conclude that ease of intubation, cough suppression, comfort score and sedation scale were better with Dexmedetomidine.

\section{KEY WORDS}

Fiberoptic Bronchoscope, Dexmedetomidine, Fentanyl, Midazolam.

HOW TO CITE THIS ARTICLE: Murugesan K, Rajkumar P. Comparison between dexmedetomidine and a combination of midazolam and fentanyl for sedation during awake fiberoptic intubation. A prospective randomized parallel group double-blinded study. J. Evolution Med. Dent. Sci. 2018;7(42):4560-4565, DOI: 10.14260/jemds/2018/1017

\section{BACKGROUND}

Peter Murphy, in England, in 1965 used a fiberoptic choledocosope to intubate nasally a patient with Still's

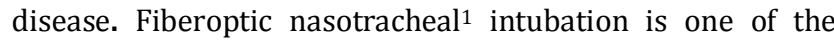
techniques available for the management of patients with difficult airways. Fiberoptic and video technologies are widely used for airway management at recent times. Awake Fiberoptic Intubation (AFOI) ${ }^{2}$ is indicated for patients with anticipated difficult airways because of their anatomy, airway trauma, morbid obesity and unstable cervical spine injuries. This $^{3}$ procedure is providing adequate sedation and anxiolysis while maintaining a patent airway and adequate ventilation, especially with difficult or critical airways. Hence, there is need for an ideal sedation regimen which would provide patient comfort, blunting of airway reflexes, patient cooperation, haemodynamic stability, amnesia and maintenance of a patent airway with spontaneous ventilation. This study compares the effectiveness and safety of dexmedetomidine with a combination of fentanyl and

'Financial or Other Competing Interest': None.

Submission 08-09-2018, Peer Review 02-10-2018,

Acceptance 08-10-2018, Published 15-10-2018.

Corresponding Author:

Dr. P. Rajkumar,

52/6, K. S. Apartment, Brindhavan Road, $4^{\text {th }}$ Cross,

Fairlands, Salem-636016, Tamilnadu, India.

E-mail: drrajkumarmo@gmail.com

DOI: $10.14260 /$ jemds $/ 2018 / 1017$

\section{(c) $(1) \$$}

midazolam for procedural sedation during awake fiberoptic intubation.

\section{MATERIALS AND METHODS}

Based on the previous study, 40 adult patients of both sexes within the age group of 25 to 50 years belonging to ASA 1 and 2 physical health status undergoing thyroid surgery were taken for convenience. This study was conducted in Govt. Dharmapuri Medical College, Dharmapuri from 2014 - 15. This was a single centre, prospective, randomised, parallel group, double-blinded study. To compare the effectiveness and safety of dexmedetomidine with a combination of fentanyl and midazolam for procedural sedation during awake fiberoptic intubation. Ethical Committee clearance was duly obtained from the hospital.

They were randomised using computer generated random numbers and allocated into two groups, Group D and Group FM as follows-

Group D: Received $1 \mathrm{mcg} / \mathrm{kg}$ of Dexmedetomidine administered over 10 mins followed by infusion dose of 0.7 $\mathrm{mcg} / \mathrm{kg} / \mathrm{hr}$.

Group FM: $2 \mathrm{mcg} / \mathrm{kg}$ of Fentanyl with $40 \mathrm{mcg} / \mathrm{kg}$ of midazolam over 10 mins followed by an infusion of normal saline.

The study was carried out in a double-blinded fashion. The patients on whom study was conducted were blinded and they did not know what drug they were administered. 
The drugs, both for bolus administration and infusion was prepared by an anaesthesiologist who was not involved in the study and hence the investigator who conducted the study was also blinded.

\section{Inclusion Criteria}

1. Age: $>25$ years $<50$ years.

2. ASA (American Society of Anaesthesiologists) 1 and 2 patients.

3. BMI: 20 - 30.

4. Patients undergoing thyroid surgery with euthyroid status.

\section{Exclusion Criteria}

1. Patient refusal.

2. Emergency surgeries.

3. Difficult airway.

4. Coagulopathies or any bleeding disorder.

5. Fracture base of skull.

6. Ischaemic heart disease/ Valvular heart disease/ arrhythmia or any conduction abnormalities. ${ }^{4}$

7. Known hypersensitivity to any of the study drugs.

8. Raised intracranial pressure.

9. Uncontrolled seizure disorder.

10. Known psychiatric illness receiving treatment in the past two weeks, where either dexmedetomidine or benzodiazepine administration is contraindicated.

11. Heart rate $<50 \mathrm{bpm}$ and Systolic blood pressure $<90$ mmHg.

12. Patients with respiratory system disorders, renal disorders and liver disorders.

\section{Procedure}

After pre-anaesthetic evaluation, 5 the more patent nostril (right or left sided) was identified. Inj. Glycopyrrolate $0.2 \mathrm{mg}$ intramuscularly was given as premedicant 45 mins before the procedure. Nasal and oral part of airway was anaesthetised by means of nasal packing and oral gargling with $4 \%$ Lignocaine, 15 mins before the start of procedure. 6 Nasal packing was done with 4 cotton pledgets soaked in $4 \mathrm{~mL}$ of 4\% Lignocaine mixed with adrenaline (1: 200000 dilution), two each for both the nostrils. Oral gargling was performed with $2 \mathrm{~mL}$ of $4 \%$ lignocaine. IV infusion of ringer lactate was started in the non-dominant arm after securing intravenous access. ECG, NIBP, $\mathrm{SpO}_{2}$ monitors were connected to the patient and $\mathrm{ETCO}_{2}$ after intubation. Anaesthetist who is experienced and well trained with fiberoptic scope and a skilled technician was called for and made ready in case if any help is needed. Fiberoptic scope, light source and appropriately sized endotracheal tubes were kept ready. All the components of Boyle's checklist were verified and ensured that nothing is missed before administering the drug.

Baseline heart rate, BP, SpO2 were recorded and noted down after which the bolus drug, 7 Dexmedetomidine or Fentanyl and midazolam based on the group was administered over 10 minutes followed by infusion. Sedation level was graded as 1, 2, 3 and 4. Intubation commenced when sedation level reached grade 2 . Local anaesthetic was sprayed as the fiberoptic scope went past the oropharynx, after the glottis was visualised. Time taken for ${ }^{8}$ intubation, ease of intubation and comfort scores of the patient were noted down. Haemodynamic variables like heart rate, SpO2, systolic BP, diastolic BP, mean arterial pressure and respiratory rate were noted at the end of intubation, 6th, 8th and 10th minute after the procedure. After which patients were observed for the following secondary outcomes.

\section{Statistical Analysis}

Data was analysed using Statistical Package for Social Science Sigma Stat 3.5 version (2012). Using this software frequencies, percentage, mean and standard deviation was calculated by Student's ' $t$ ' test and Chi-square test. The comparison of proportion was calculated using independent ' $\mathrm{t}$ ' test. The $\mathrm{P}$ value of $<0.05$ was taken as significant.

\section{RESULTS}

\begin{tabular}{|c|c|c|c|c|}
\hline Group & Mean & SD & P value & T value \\
\hline Fent and Midaz & 36.6 & 13.03 & \multirow{2}{*}{0.513} & \multirow{2}{*}{0.66} \\
\cline { 1 - 3 } Dexmed & 39.2 & 11.85 & & \\
\hline \multicolumn{4}{|c|}{ Table 1. Showing the Mean, Standard Deviation, P and T } \\
value regarding to Age \\
\hline
\end{tabular}

The age incidence of our study belonged to patients of all ages in the range of 25 to 50 years as shown in Table 1 with mean falling in the mid-range.

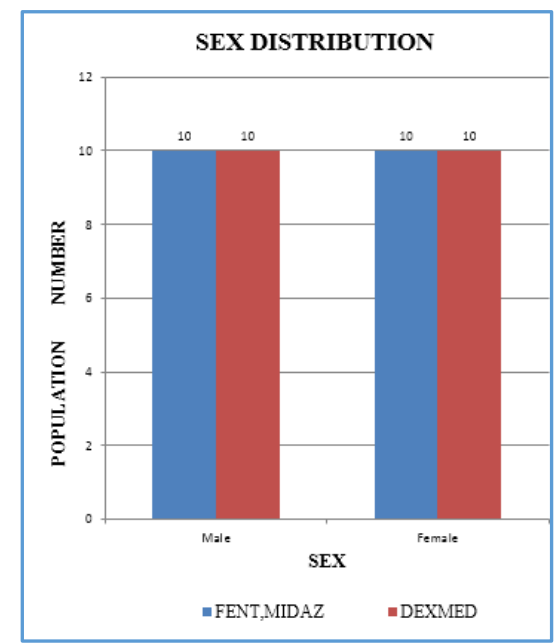

Figure 1. Comparison of Sex distribution between the Two Groups

The male and female populations of our study was distributed equally with ten in each group and in each category.

\begin{tabular}{|c|c|c|c|c|}
\hline Group & Mean & SD & P value & T value \\
\cline { 1 - 4 } $\begin{array}{c}\text { Fent and } \\
\text { Midaz }\end{array}$ & 62.45 & 13.14 & 0.783 & 0.278 \\
\cline { 1 - 3 } Dexmed & 63.75 & 16.28 & & \multirow{5}{|c|}{ Groups } \\
\hline Table 2. Comparison of Weight distribution between Two \\
\hline
\end{tabular}

\begin{tabular}{|c|c|c|c|c|}
\hline Group & Mean & SD & P value & T value \\
\hline Fent and Midaz & 22.46 & 4.38 & \multirow{2}{*}{0.587} & 0.548 \\
\hline Dexmed & 23.28 & 5.05 & & \\
\hline \multicolumn{6}{|c|}{ Table 3. Comparison of BMI distribution between Two } \\
Groups \\
\hline
\end{tabular}

\begin{tabular}{|c|c|c|c|c|}
\hline Group & Mean & SD & P value & T value \\
\hline Fent and Midaz & 165.5 & 5.79 & \multirow{2}{*}{0.672} & 0 \\
\cline { 1 - 3 } Dexmed & 164.65 & 6.77 & & \\
\hline Total & & & & \\
\hline Table 4. Comparison of Height distribution between Two \\
Groups \\
\hline
\end{tabular}


The difference in height, weight and BMI of the study population between the two study groups were comparable, but not statistically significant.

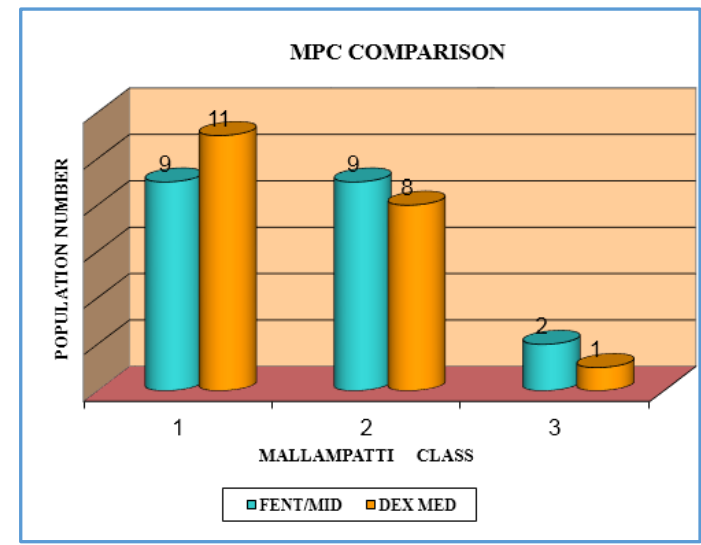

Figure 2. Comparing the distribution of Population based on their Mallampati Airway Class

Fifty percent of the population in our study group belong to Mallampati class 1 , above 40 percent to class 2 and remaining to class 3 . None of our study population belonged to Mallampati class four airway.

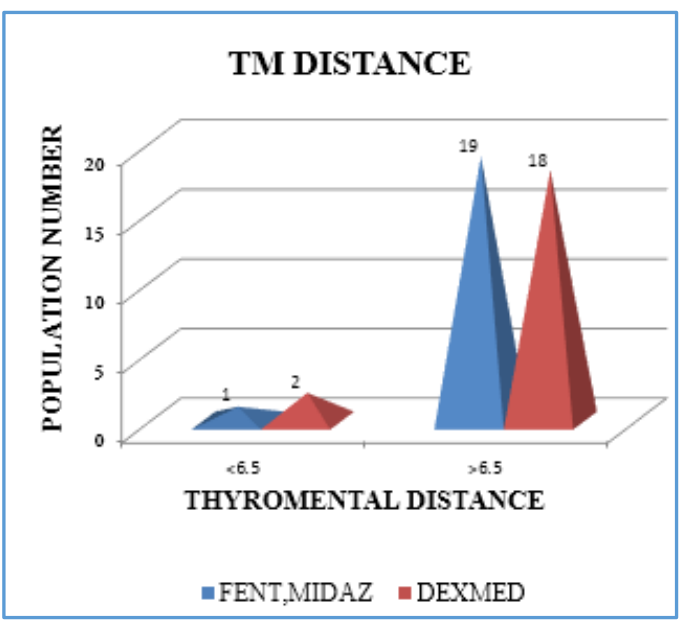

Figure 3. Comparing the distribution of Population based on Thyromental Distance

Over 90 percentage of our population had TMD $>6.5$.

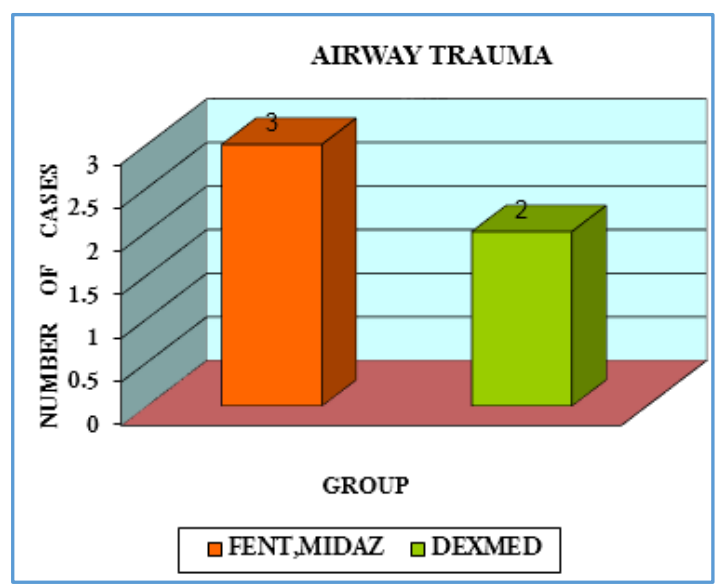

Figure 4. Comparing the Incidence of Airway Injury between the Two Groups
Ninety five percent and ninety percent of the population did not have Airway trauma in Group D and Group FM respectively.

Statistical Significance existed between Two Groups in terms of-

- Intubation time in seconds.

- Sedation scale.

- Comfort score.

- Haemodynamic variables.

\begin{tabular}{|c|c|c|c|c|}
\hline Group & Mean & SD & P value & T value \\
\hline Fent and Midaz & 1.55 & 0.76 & \multirow{2}{*}{0.005} & \multirow{2}{*}{2.97} \\
\cline { 1 - 3 } Dexmed & 2.15 & 0.49 & & \\
\cline { 1 - 2 } Table 5. Comparison of Sedation Scale between Two \\
Groups \\
\hline
\end{tabular}

Dexmedetomidine group had a better sedation score when compared with fentanyl midazolam group. The sedation score was adequate providing the patient with anxiolysis and a good conscious sedation with amnesia as well.

\begin{tabular}{|c|c|c|c|c|}
\hline Group & Mean & SD & P value & T value \\
\hline Fent \& Midaz & 20.87 & 4.27 & \multirow{2}{*}{$<0.001$} & 4.45 \\
\hline Dexmed & 15.92 & 2.56 & & \\
\hline \multicolumn{4}{|c|}{ Table 6. Comparison of Intubation Time between Two } \\
\multicolumn{4}{|c|}{} \\
\hline
\end{tabular}

Except for 3 patients, the intubation time was less in dexmedetomidine group when compared with fentanylmidaz group with statistical significance $(\mathrm{P}$ value being $<0.001$ ).

\begin{tabular}{|c|c|c|c|c|}
\hline Group & Mean & SD & P value & T value \\
\hline Fent and Midaz & 15.95 & 1.73 & \multirow{2}{*}{$<0.001$} & \multirow{2}{*}{9.82} \\
\hline Dexmed & 11.3 & 1.22 & & \\
\hline \multicolumn{5}{|c|}{ Table 7. Showing the Comparison of Comfort Score } \\
between Two Groups \\
\hline
\end{tabular}

Dexmedetomidine group patients were better comfortable with the procedure than fentanyl midazolam group. Comfort score was calculated out of 35 based on 7 entities. Dexmed group had a mean value of 11.3 when compared with fentanyl midazolam group which had a mean value of 15.95 (lower the comfort score, better the patient was).

In case of haemodynamic variables again, dexmedetomidine group patients had better haemodynamic scores than fentanyl midazolam group patients.

\begin{tabular}{|c|c|c|c|c|c|c|}
\hline \multirow{2}{*}{ Time } & \multicolumn{2}{|c|}{$\begin{array}{c}\text { Fent and } \\
\text { Midaz }\end{array}$} & \multicolumn{2}{c|}{ Dexmed } & & \\
\cline { 2 - 7 } & Mean & SD & Mean & SD & $\begin{array}{c}\text { P } \\
\text { value }\end{array}$ & $\begin{array}{c}\text { T } \\
\text { value }\end{array}$ \\
\hline Baseline & 84.6 & 8.78 & 82.95 & 11.66 & 0.616 & 0.505 \\
\hline $\begin{array}{c}\text { Before } \\
\text { intubation }\end{array}$ & 83.5 & 6.76 & 81 & 7.64 & 0.28 & 1.09 \\
\hline $\begin{array}{c}\text { After } \\
\text { intubation }\end{array}$ & 115.4 & 9.03 & 101.9 & 9.39 & $<0.001$ & 4.63 \\
\hline 6th min & 103.9 & 11.36 & 94.25 & 9.65 & 0.006 & 2.89 \\
\hline 8th min & 95.55 & 8.13 & 89.55 & 7.84 & 0.023 & 2.37 \\
\hline 10th min & 85.2 & 10.47 & 82.4 & 7.79 & 0.343 & 0.96 \\
\hline Table 8. Comparison of Pulse Rate Scores between Two \\
Groups
\end{tabular}


Pulse Rate Distribution

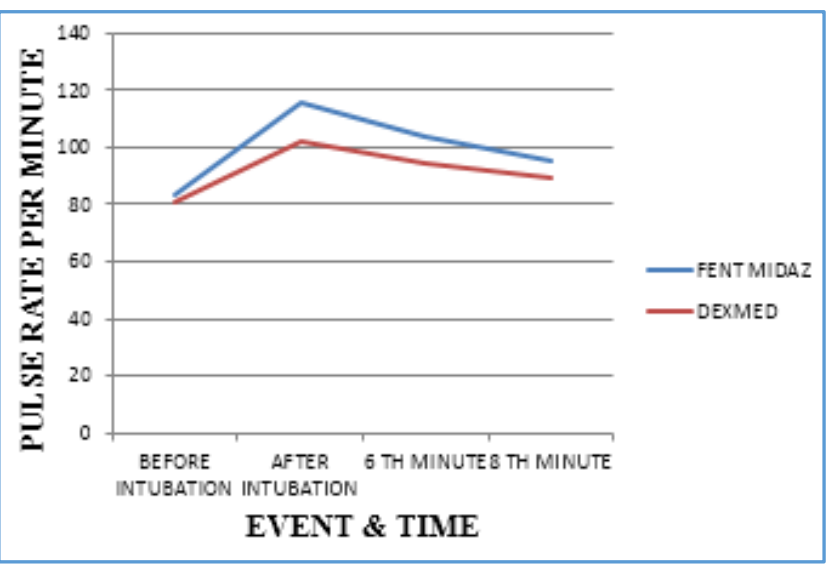

Figure 5. Line Graph showing Pulse Rate Variations among Two Groups

After intubation, $6^{\text {th }}$ and $8^{\text {th }}$ minute pulse rate scores were statistically significant with $\mathrm{P}$ value being $<0.001,0.006$, 0.023 respectively.

\begin{tabular}{|c|c|c|c|c|c|c|}
\hline \multirow{2}{*}{ Time } & \multicolumn{2}{|c|}{ Fent, Midaz } & \multicolumn{2}{c|}{ Dexmed } & & \\
\cline { 2 - 7 } & Mean & SD & Mean & SD & $\begin{array}{c}\text { P } \\
\text { value }\end{array}$ & $\begin{array}{c}\text { T } \\
\text { value }\end{array}$ \\
\hline Baseline & 125.8 & 16.72 & 126.05 & 13.97 & 0.959 & 0.051 \\
\hline $\begin{array}{c}\text { Before } \\
\text { intubation }\end{array}$ & 119.75 & 15.01 & 124.35 & 14.05 & 0.323 & 1.001 \\
\hline $\begin{array}{c}\text { After } \\
\text { intubation }\end{array}$ & 149.25 & 12.47 & 140.95 & 15.01 & 0.065 & 1.902 \\
\hline 6th min & 142.6 & 14.73 & 133.75 & 12.37 & 0.047 & 2.06 \\
\hline 8th min & 131.4 & 17.03 & 129.9 & 9.86 & 0.744 & 0.329 \\
\hline 10th min & 122.75 & 20.79 & 126 & 13.33 & 0.562 & 0.586 \\
\hline \multicolumn{7}{|c|}{ Table 9. Comparison of Systolic BP Scores between Two } \\
\multicolumn{7}{|c|}{ Groups } \\
\hline
\end{tabular}

\section{Systolic BP Distribution}

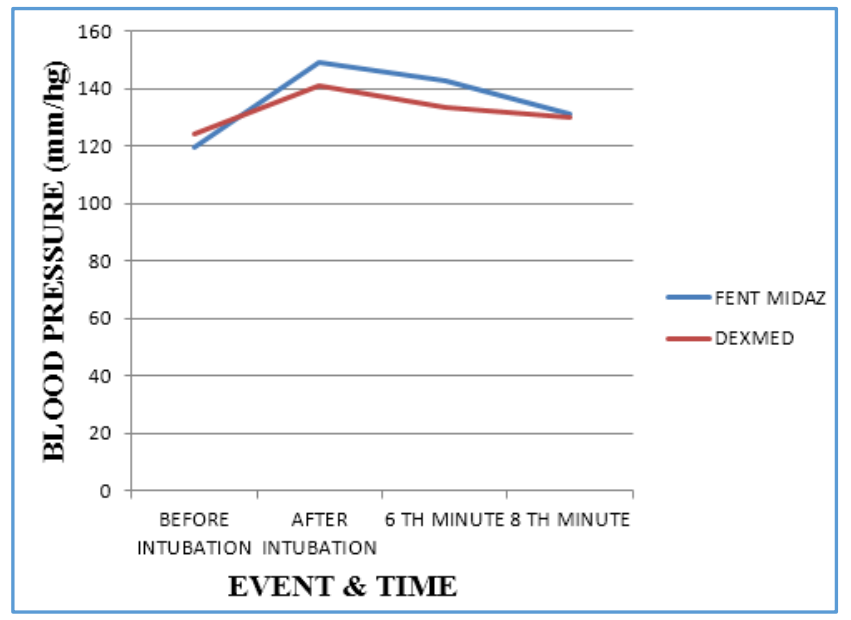

Figure 6. Comparing Systolic BP variations between Two Groups

After intubation and 6th minute scores were statistically significant.

\begin{tabular}{|c|c|c|c|c|c|c|}
\hline \multirow{2}{*}{ Time } & Fent, Midaz & \multicolumn{2}{|c|}{ Dexmed } & & \\
\cline { 2 - 7 } & Mean & SD & Mean & SD & $\begin{array}{c}\text { P } \\
\text { value }\end{array}$ & T value \\
\hline Baseline & 81.9 & 13.56 & 78.3 & 10.33 & 0.351 & 0.945 \\
\hline $\begin{array}{c}\text { Before } \\
\text { intubation }\end{array}$ & 76.9 & 11.25 & 77.35 & 12.99 & 0.907 & 0.117 \\
\hline $\begin{array}{c}\text { After } \\
\text { intubation }\end{array}$ & 93.55 & 13.97 & 85.8 & 9.6 & 0.037 & 2.16 \\
\hline 6th min & 89.3 & 13.45 & 80.8 & 11.15 & 0.036 & 2.17 \\
\hline 8th min & 85.6 & 12.83 & 79.75 & 9.78 & 0.113 & 1.62 \\
\hline 10th min & 79 & 15.54 & 75.65 & 10.06 & 0.424 & 0.809 \\
\hline Table 10. Comparison of Diastolic BP Scores between the \\
Two Groups \\
\hline
\end{tabular}

\section{Diastolic BP Distribution}

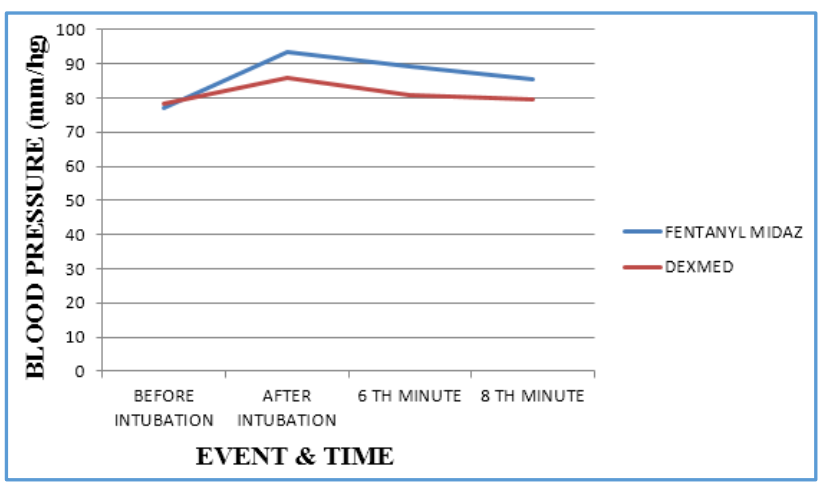

Figure 7. Comparing Diastolic BP variations between the Two Groups

After intubation and 6th minute scores were statistically significant with $P$ value being 0.037 and 0.036 respectively.

\begin{tabular}{|c|c|c|c|c|c|c|}
\hline \multirow{2}{*}{ Time } & Fent, Midaz & \multicolumn{2}{|c|}{ Dexmed } & & \\
\cline { 2 - 7 } & Mean & SD & Mean & SD & P value & T value \\
\hline Baseline & 96.5 & 15.02 & 92.3 & 21.84 & 0.483 & 0.709 \\
\hline $\begin{array}{c}\text { Before } \\
\text { intubation }\end{array}$ & 91.3 & 11.92 & 95.4 & 14.01 & 0.325 & 0.997 \\
\hline $\begin{array}{c}\text { After } \\
\text { intubation }\end{array}$ & 116.55 & 14.45 & 105.5 & 12.5 & 0.014 & 2.58 \\
\hline 6th min & 109.6 & 15.86 & 99.2 & 11.5 & 0.023 & 2.37 \\
\hline 8th min & 101.4 & 15.56 & 97.9 & 9.09 & 0.39 & 0.869 \\
\hline 10th min & 93.65 & 18.37 & 93.6 & 10.04 & 0.992 & 0.011 \\
\hline Table 11. Comparing MAP (Mean Arterial Pressure) \\
between the Two Groups \\
\hline
\end{tabular}

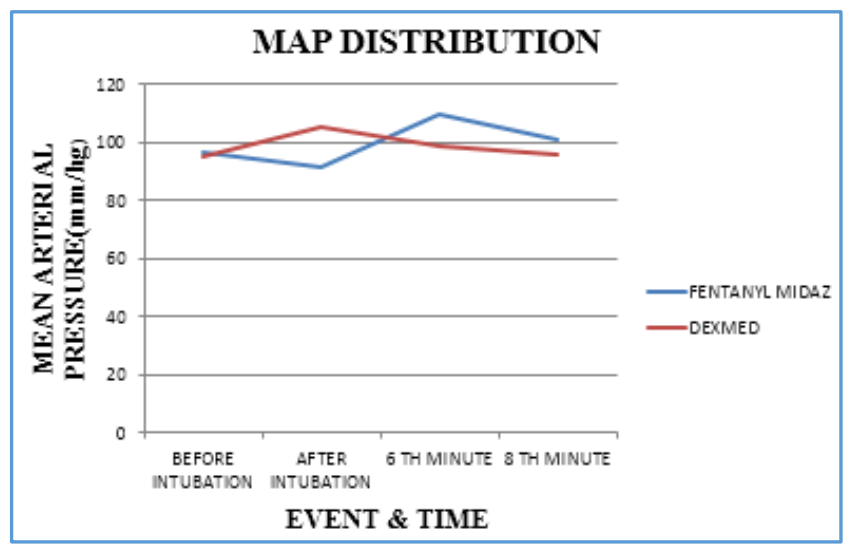

Figure 8. Comparing MAP variations between Two Groups 
After intubation and 6th minute values were significant with $P$ value being 0.014 and 0.023 respectively.

\begin{tabular}{|c|c|c|c|c|c|c|}
\hline \multirow{2}{*}{ Time } & \multicolumn{2}{|c|}{ Fent Midaz } & \multicolumn{2}{|c|}{ Dexmed } & & \\
\cline { 2 - 7 } & Mean & SD & Mean & SD & P value & $\begin{array}{c}\text { T } \\
\text { value }\end{array}$ \\
\hline Baseline & 100 & & 100 & & 1 & \\
\hline $\begin{array}{c}\text { Before } \\
\text { intubation }\end{array}$ & 100 & & 100 & & 1 & \\
\hline $\begin{array}{c}\text { After } \\
\text { intubation }\end{array}$ & 97.5 & 2.67 & 99.2 & 1.74 & 0.022 & 2.38 \\
\hline 6th min & 99.4 & 0.41 & 99.85 & 0.49 & 0.003 & 3.15 \\
\hline 8th min & 100 & & 100 & & 1 & \\
\hline 10th min & 100 & & 100 & & 1 & \\
\hline Table 12. Comparison of SpO \\
Groups Scores between the Two
\end{tabular}

\section{$\mathrm{SPO}_{2}$ Distribution}

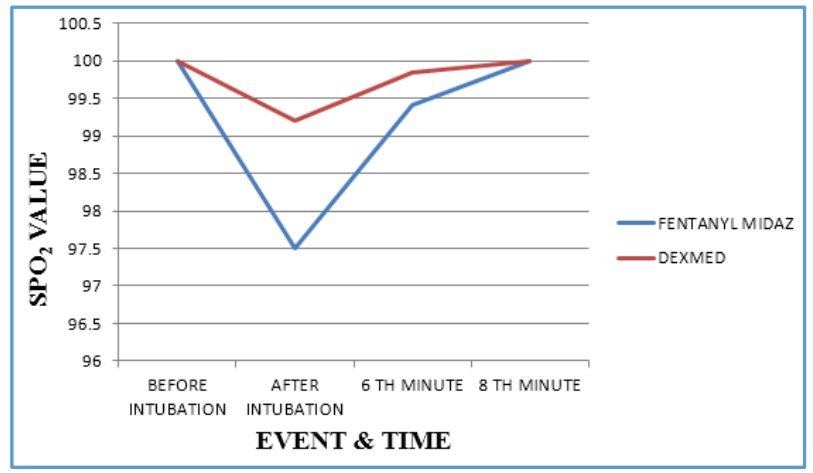

Figure 9. Showing $\mathrm{SpO}_{2}$ variations between Two Groups

After intubation and 6th minute were statistically significant with $P$ value being 0.022 and 0.003 respectively.

\section{DISCUSSION}

Awake fiberoptic intubation, ${ }^{9}$ one of the modalities in difficult airway management is an unpleasant procedure which definitely needs an ideal sedative regimen satisfying patient in all aspects by providing adequate analgesia, amnesia, anxiolysis, anti-sialogogue, better respiratory and haemodynamic parameters.10 Fentanyl midazolam combination may provide adequate analgesia, amnesia, anxiolysis but is known to produce apnoea and hypoxaemia even in healthy volunteers. But dexmedetomidine, ${ }^{11}$ a recently introduced drug, an alpha- 2 adrenoreceptor agonist seems to be satisfying all the patient's needs in all aspects.

In view of existing controversies and lack of consensus in previous literatures, this study was carried out over a one year period with the principal aim of comparing dexmedetomidine ${ }^{12}$ alone with fentanyl-midazolam combination as an ideal agent for providing sedation for AFOI. In this study, we have shown that Dexmedetomidine ${ }^{13}$ convincingly is a superior and better drug in terms of providing sedation for awake fiberoptic intubation in all aspects. The plane of sedation provided by this drug was excellent such that it neither produced a deep sedation making the patient well asleep depressing his respiration nor a superficial plane where the patient is anxious and agitated. It was an intermediate plane where the patient was conscious, responding to commands, calm with better haemodynamics and respiratory parameter.
Quoting other's literature, Bergese et al in his study has shown that patients belonging to dexmedetomidine group were more satisfied and comfortable than the midazolam group. Further, in our study dexmedetomidine group patient had better comfort score when compared with fentanyl midazolam group. ${ }^{14}$ Comfort score was calculated based on 7 parameters which were calmness, alertness, crying, physical movement, respiratory response, facial tension and muscle tone. The lower the score, the better the patient was.

Also, the patients belonging to dexmedetomidine group had less airway trauma when compared with fentanyl midazolam indicating Group D patients were better prepared for the procedure. Intubation time in dexmedetomidine group patients was faster when compared with fentanyl midazolam group, which tells that Group D patients were easier to intubate as they were more cooperative and calmer.

Dexmedetomidine group patients also had better haemodynamics when compared with fentanyl and midazolam group. Further Dexmedetomidine group had better respiratory parameters in terms of Sp02.15 Midazolam especially in combination with fentanyl is known for its respiratory depression and decrease in Sp02, whereas dexmedetomidine group has respiratory sparing effect even in high doses. Bailey et al too had quoted in his literature that fentanyl and midazolam combination produces respiratory depression and hypoxia. Kamibyashi et al has quoted that dexmedetomidine ${ }^{16}$ has additional antisialagogue effect making intubation easier and intubation time shorter.

\begin{tabular}{|c|c|}
\hline Study & Inference \\
\hline $\begin{array}{c}\text { Bailey et } \\
\text { al }\end{array}$ & $\begin{array}{c}\text { Fentanyl and midazolam use has produced } \\
\text { significant hypoxia and apnoea even in healthy } \\
\text { adult volunteers. }\end{array}$ \\
\hline $\begin{array}{c}\text { Bergese } \\
\text { et al }\end{array}$ & $\begin{array}{c}\text { Dexmedetomidine group patients were more calm, } \\
\text { cooperative and satisfied when compared with } \\
\text { others. }\end{array}$ \\
\hline $\begin{array}{c}\text { Tsai } \\
\text { et al }\end{array}$ & $\begin{array}{c}\text { Respiratory depression is lesser with } \\
\text { dexmedetomidine group when compared with } \\
\text { propofol group. }\end{array}$ \\
\hline $\begin{array}{c}\text { Avitsian } \\
\text { et al }\end{array}$ & $\begin{array}{c}\text { Dexmedetomidine had better intubating conditions } \\
\text { in patients with cervical spine injury. }\end{array}$ \\
\hline $\begin{array}{c}\text { Chu } \\
\text { et al }\end{array}$ & $\begin{array}{c}\text { In oral cancers for whom intubation was difficult, } \\
\text { dexmedetomidine was very much efficacious. }\end{array}$ \\
\hline $\begin{array}{c}\text { Bloor } \\
\text { et al }\end{array}$ & $\begin{array}{c}\text { Dexmedetomidine has a biphasic blood pressure } \\
\text { response, initial hypertension due to } \\
\text { vasoconstriction of peripheral vessels. }\end{array}$ \\
\hline & Table 13. Comparison of Similar Studies \\
\hline
\end{tabular}

\section{CONCLUSION}

We conclude that dexmedetomidine is a safe and highly efficacious drug in providing sedation, amnesia, anxiolysis, analgesia, better haemodynamics without producing respiratory depression for awake fiberoptic intubation. We also conclude that ease of intubation, cough suppression, comfort score and sedation scale was better with dexmedetomidine.

\section{REFERENCES}

[1] Ovassapian A, Yelich SJ, Dykes MH, et al. Fiberoptic nasotracheal intubation--incidence and causes of failure. Anesth Analg 1983;62(7):692-5.

[2] Shorten GD, Roberts JT. The prediction of difficult intubation. Anesthesiol Clin North America 1991;9:637. 
[3] Reed AF, Han DG. Preparation of the patient for awake intubation. Anesthesiol Clin North America 1991;9:6981.

[4] Kulka PJ, Tryba M, Zenz M. Difficult airway management in a patient with severe aortic stenosis, coronary artery disease and heart failure. J Clin Anesth 2002;14(2):150-3.

[5] Sanchez A, Iyer RR, Morrison DE. Preparation of the patient for awake intubation. In: Hagberg CA, ed. Benumof's airway management: principles and practice. Philadelphia: Mosby-Elsevier 2007:255-80.

[6] Naguib M, Magboul MM, Samarkandi AH, et al. Adverse effects and drug interactions associated with local and regional anaesthesia. Drug Saf 1998;18(4):221-50.

[7] Masoud SM, El-Tohamy SA, Amin AA. Dexmedetomidine versus midazolam/propofol or midazolam/fentanyl for conscious sedation during awake fiberoptic intubation. Ains Shams J Anaesthesiol 2013;6(1):30-7.

[8] Baraka A, Salem MR. Preoxygenation. In: Hagberg CA, ed. Benumof's Airway management: principles and practice. Philadelphia: Mosby-Elsevier 2007:303-18.

[9] Lee JH, Han SW, Kim YY, et al. Sedation and hemodynamic stability during fiberoptic awake nasotracheal intubation: comparison between propofol infusion and intravenous boluses of fentanyl and midazolam. Korean J Anesthesiol 1997;33(4):741-9.
[10] Mondal S, Ghosh S, Bhattacharya S, et al. Comparison between dexmedetomidine and fentanyl on intubation conditions during awake fiberoptic bronchoscopy: a randomized double-blind prospective study. J Anaesthesiol Clin Pharmacol 2015;31(2):212-6.

[11] Scheinin M, Schwinn DA. The locus coeruleus. Site of hypnotic actions of alpha 2-adrenoceptor agonists? Anesthesiology 1992;76(6):873-5.

[12] Chu KS, Wang FY, Hsu HT, et al. The effectiveness of dexmedetomidine infusion for sedating oral cancer patients undergoing awake fibreoptic nasal intubation. Eur J Anaesthesiol 2010;27(1):36-40.

[13] Cateno D. Comparison of efficacy of dexmedetomidine with remifentanil for AFOI- A randomised double blinded pilot study. J Anaesthesiol Clin Pharmacol 2014;25(8):350-60.

[14] Belleville JP, Ward DS, Bloor BC, et al. Effects of intravenous dexmedetomidine in humans. I. Sedation, ventilation and metabolic rate. Anesthesiology 1992;77(6):1125-33

[15] Bailey PL, Pace NL, Ashburn MA, et al. Frequent hypoxemia and apnea after sedation with midazolam and fentanyl. Anesthesiology 1990;73(5):826-30.

[16] Ebert TJ, Hall JE, Barney JA, et al. The effect of increasing plasma concentrations of dexmedetomidine in humans. Anesthesiology 2000;93(2):382-94. 